\title{
ESTUDO DA COBERTURA VEGETAL DO MUNICÍPIO DE GUAIÚBA/CE COM BASE NA UTILIZAÇÃO DOS ÍNDICES DE VEGETAÇÃO SAVI E NDVI
}

Túlio Viana Bandeira ${ }^{1}$ Maria Lúcia Brito da Cruz ${ }^{2}$

Resumo: A aplicação dos índices de vegetação são componentes essenciais na compreensão da cobertura vegetal ao investigar a paisagem de um dado espaço. Nesse sentido, o presente artigo objetiva-se em analisar a atividade vegetacional do município de Guaiúba/CE, através da aplicação dos índices de vegetação (SAVI e NDVI). O percurso metodológico se ateve na geração de tais índices, interpolação e produção cartográfica. Como resultados da pesquisa denota-se a demonstração da investigação pluviométrica acumulada do município de Guaiúba, bem como a quantificação das classes de atividades fotossintéticas geradas pelos índices de vegetação. Logo, a compreensão dos índices, permitem estudos diversos, tanto no âmbito geográfico, como na formulação de ações de planejamento ambiental.

Palavras-chave: Atividade vegetacional. Análise pluviométrica. SAVI. NDVI. Guaiúba.

\section{STUDY OF VEGETABLE COVERAGE IN THE MUNICIPALITY OF GUAIÚBA / CE BASED ON THE USE OF SAVI AND NDVI VEGETATION INDEXES}

Abstract: The application of vegetation indexes are essential components in comprehension vegetation cover when investigating the landscape of a given space. In this sense, this article aims to analyze the vegetation activity in the municipality of Guaiúba / CE, through the application of vegetation indices (SAVI and NDVI). The methodological path has focused on the generation of such indexes, interpolation and cartographic production. The research results show the demonstration of accumulated rainfall investigation in the municipality of Guaiúba, as well as the quantification of the classes of photosynthetic activities generated by the vegetation indexes. Therefore, the comprehension of the indexes allows for diverse studies, both in the geographical scope, as well as in the formulation of environmental planning actions.

Keywords: Vegetation activity. Pluviometric analysis. SAVI. NDVI. Guaiúba.

\section{ESTUDIO DE COBERTURA VEGETAL EN EL MUNICIPIO DE GUAIÚBA / CE BASADO EN EL USO DE ÍNDICES DE VEGETACIÓN SAVI E NDVI}

Resumen: La aplicación de índices de vegetación son esenciales para comprender la cubierta vegetal cuando se investiga el paisaje de un espacio dado. En este sentido, el artículo pretende analizar la actividad de la vegetación en el municipio de Guaiúba / CE, mediante la aplicación de índices de vegetación (SAVI y NDVI). La ruta metodológica se ha centrado en la generación de dichos índices, la interpolación y la producción cartográfica. Los resultados de la investigación muestran la demostración de la investigación de lluvia acumulada en el municipio de Guaiúba, así como la cuantificación de las clases de actividades fotosintéticas

\footnotetext{
1 Universidade Estadual do Ceará, Centro de Ciência e Tecnologia, Fortaleza, Brasil, tulioviana18@gmail.com, https://orcid.org/0000-0001-8582-9667

2 Universidade Estadual do Ceará, Centro de Ciência e Tecnologia, Fortaleza, Brasil, mlbcruz@gmail.com, https://orcid.org/0000-0002-2202-923X
} 
generadas por los índices de vegetación. La comprensión de los índices, permite diversos estudios, tanto en el ámbito geográfico, como en la formulación de acciones de planificación ambiental.

Palabras clave: Actividad de vegetación. Análisis pluviométrico. SAVI. NDVI. Guaiúba.

\section{Introdução}

A cobertura vegetal vem sendo estudada ao longo de vários anos, principalmente depois da descoberta de que, através da Radiação Eletromagnética (REM), os vegetais extraem parte de energia para sobreviver, após isso, a interação entre radiação e vegetação passou a ser estudada detalhadamente (PONZONI, 2001).

Uma das técnicas desenvolvidas para expressar essas relações do comportamento espectral da vegetação são os índices de vegetação. De acordo com Jensen (2009), o primeiro índice de vegetação criado foi a Razão Simples (RS), que demonstra a razão entre o fluxo refletido no infravermelho próximo e o fluxo refletido no vermelho. Posteriormente, esse índice foi desenvolvido e, com isso, criou-se o Índice de Vegetação por Diferença Normalizada (NDVI). A utilização dos índices detecta a atividade fotossintética da vegetação

No presente artigo foram utilizados o Índice de Vegetação da Diferença Normalizada (NDVI) e Índice de Vegetação Ajustado ao Solo (SAVI), os quais permitem uma melhor obtenção e compreensão dos parâmetros biofísicos da vegetação, tais como: sua biomassa, porcentagem de cobertura de solo exposto, corpos hídricos entre outros. Destaque-se principalmente dois canais do espectro eletromagnético, a região do visível e do infravermelho próximo, os quais segundo Rosa (2007) obtém mais de 90\% da resposta espectral da vegetação.

Essa análise da vegetação foi realizada do município de Guaiúba (Mapa 1). Quanto à localização geográfica, o mesmo está inserido na Região Metropolitana de Fortaleza, com distância de $36 \mathrm{~km}$ da capital. Segundo o Instituto Brasileiro de Geografia e Estatística (2020), o município possui área de 267 km² e população estimada de 26.290 habitantes.

$\mathrm{Na}$ área de estudo, inclui-se 5 Distritos além da sede, são eles: Baú, Água Verde, Itacima, Dourado e São Jerônimo. Suas coordenadas geográficas são: 4ํ02' 32.46 "S de latitude e 38 $38^{\prime} 00.55^{\prime \prime W}$ de longitude. Sua principal via de acesso é a CE-060, a qual faz conexão do interior do Estado para a capital cearense. Os outros sistemas viários são a CE-451, CE-253 e a CE-354. 
Mapa 1 - Localização do município de Guaiúba/CE

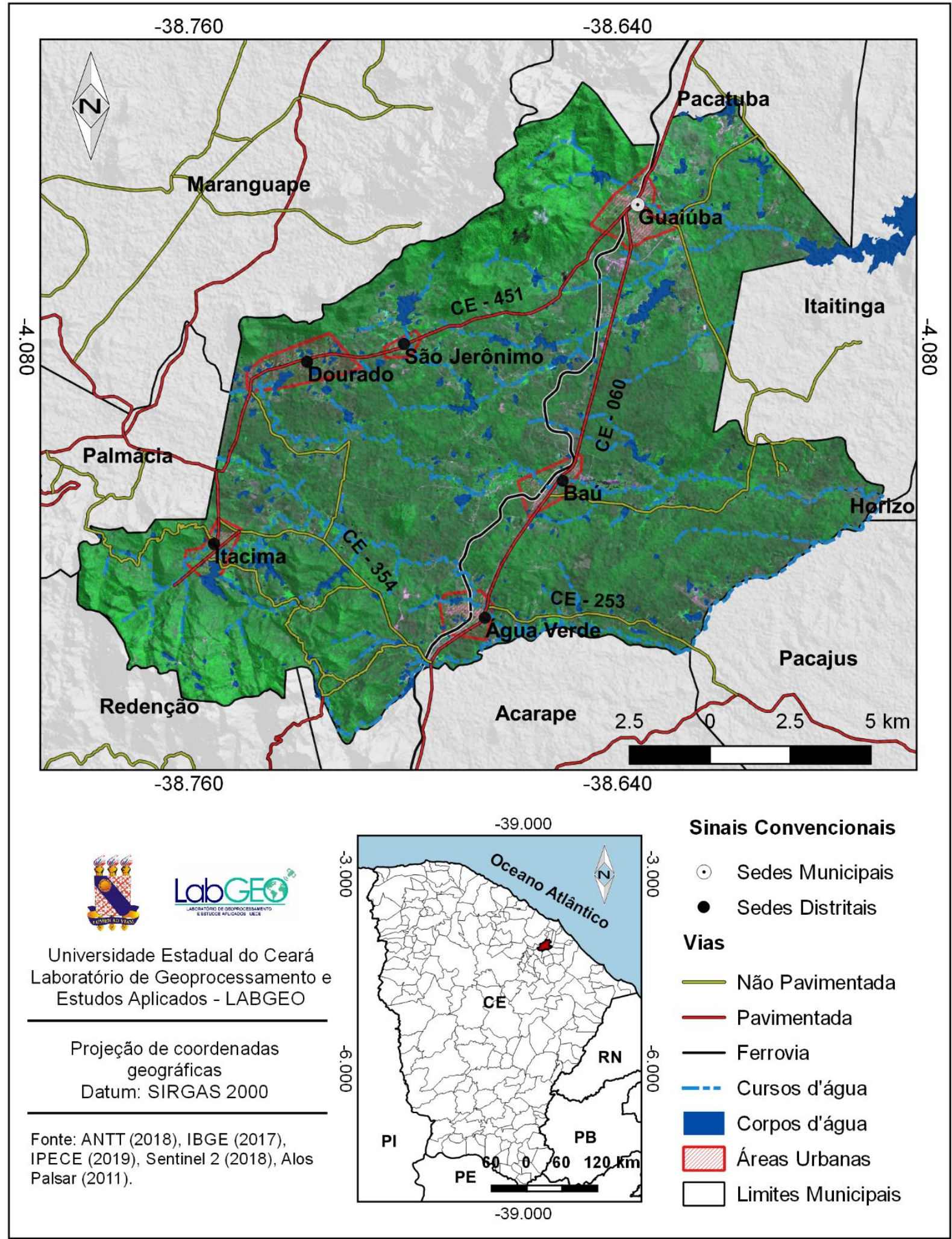

Org.: Elaborado pelo autor.

Enquanto objetivo desse trabalho, destaca-se aplicar os índices de vegetação (SAVI e NDVI) no reconhecimento e análise da atividade vegetacional do município de Guaiúba/CE. Para isso, tornou-se necessário especificamente: discutir a respeito de radiação eletromagnética e sua interação com a vegetação; relacionar 
os dados de precipitação com a distribuição da cobertura vegetal e avaliar as classes geradas através dos índices de vegetação.

Para o alcance desse objetivo, a presente discussão foi desenvolvida estruturalmente da seguinte forma: no primeiro tópico após a introdução é tratado a respeito da metodologias e dos procedimentos operacionais utilizados para a realização da pesquisa. Após isso é discutido todos os resultados levantados. Vale ressaltar que os mesmos são do ano de 2019, pois os trabalhos de campo ocorreram em junho do referido ano e as imagens de satélite são também da mesma data.

\section{Metodologia e Procedimentos Operacionais}

\section{Produção Cartográfica e geração dos Índices de Vegetação}

Em relação aos mapas, eles foram gerados através dos softwares Quantum GIS 2.18.12 e SNAP, uma vez que os referidos recursos possuem a vantagem de serem livres e gratuitos, além de operarem com base de dados geográficos.

Para a produção do mapa de localização (Mapa 1), foi utilizada a imagem de satélite do Sentinel 2 nível 2A referente às bandas 8,4 e 3. Com essas 3 bandas escolhidas, foi gerada uma composição RGB falsa-cor de 10 metros de resolução espacial. Além disso, foram inseridos os shapefiles dos limites municipais, do sistema viário, dos cursos e corpos d'água, das áreas urbanas, das sedes municipais e distritais e do sistema ferroviário. Por fim, foi criado o mapa no compositor de impressão.

No tocante ao mapa de pluviometria acumulada (Mapa 2), ele serviu de base para discutir a atividade fotossintética detectada pelos índices de vegetação, uma vez que esse dado apresenta relação com a quantidade de precipitação na área, principalmente pelo motivo da cobertura vegetal ser sensível à quantidade de chuva, de maneira que a sua absorção pelos dosséis também modifica o resultado dos índices.

O Mapa 2 foi gerado através dos dados de precipitação fornecidos pela FUNCEME. Foram utilizados 12 postos pluviométricos, são eles: Pacatuba, Palmácia, Redenção, Horizonte, Guaiúba, Itaitinga, Itaipaba, Acarape, Itacima, São Gerardo, Paco Municipal (Itaitinga) e Olho d'água. Após a tabulação dos dados de precipitação, o QGIS 2.18 foi utilizado para interpolar os pontos. O método usado 
para isso foi o IDW, em forma de representação de campo contínuo. Após a criação do raster interpolado, criou-se as isolinhas em raster $\rightarrow$ extrair $\rightarrow$ contorno. Posteriormente, foram inseridos os demais shapefiles, finalizado o mapa no compositor de impressão.

Sobre os mapas dos índices de vegetação (Mapa 3 e 4), eles foram gerados para identificar e discutir a cobertura vegetal, uma vez que, ao utilizarem as bandas do vermelho e do infravermelho próximo, detectam grande parte da atividade fotossintética da vegetação. Para geração desses mapas, é necessário corrigir as imagens de satélite utilizadas.

As correções correspondem ao reparo de perdas radiométricas em função principalmente da influência da atmosfera. De acordo com Rosa (2007), a correção de imagens é uma das mais importantes fases do processamento digital, uma vez que, caso essas imperfeições não sejam removidas, poderão ser destacadas quando o procedimento de realce das imagens acontecer.

É nessa etapa que há eliminação dos efeitos do espalhamento atmosférico, o qual produz alteração no brilho da imagem, diminuição de contraste e redução das faixas de valores digitais registrados pelo sensor. Os gases e os aerossóis (pequenas partículas em suspensão) refletem, refratam, absorvem e espalham a radiação desde sua chegada na atmosfera até quando a deixa (ZULLO JUNIOR, 1994).

Portanto, essa etapa é essencial para a exatidão dos resultados reunidos. A partir dela, são calculados os dados para a conversão da radiância, da reflectância, da calibração da imagem e das demais correções atmosféricas e geração dos índices. A imagem de satélite utilizada para geração dos índices de vegetação foi o Sentinel 2 nível 2A, categoria do satélite que já vem com as correções geradas. Dessa forma, não há necessidade de converter os números digitais para radiância e/ou reflectância para posteriormente gerar as correções atmosféricas.

O Sentinel 2 nível 2A fornece imagens ortorretificadas, que são produtos os quais passaram pelo processo de Correção de Reflectância da Base da Atmosfera (BOA) a partir de outro nível inferior, que apresenta sua correção através de um MDE para corrigir distorções geométricas da Terra, fazendo também a Correção do Topo da Atmosfera (TOA). Dessa forma, o produto utilizado apresenta duas correções: TOA e BOA. Após esses procedimentos de correção atmosférica, 
os efeitos atmosféricos de gases e aerossóis são diminuídos, permitindo, assim, melhor precisão radiométrica das imagens para a geração dos índices de vegetação.

Com as imagens do vermelho e do infravermelho próximo corrigidas, utilizou-se o SNAP para geração dos índices de vegetação no seguinte caminho: optical $\rightarrow$ thematic land processing $\rightarrow$ vegetation radiometric indices. Com os índices gerados o passo posterior foi migrar os dados para o QGIS 2.18 e inserir os shapefiles para finalizar os mapas.

Por fim, vale destacar que todos os sombreamentos utilizados nos mapas foram gerados através de imagem de radar do Alos Palsar com transparência de $85 \%$. No tocante às cores das feições presentes nos mapas, os manuais do IBGE foram consultados.

\section{Ponderação do Inverso da Distância (IDW)}

A interpolação consiste em converter dados pontuais em campos contínuos, produzindo padrões espaciais que podem ser comparados com outras entidades. Ela é utilizada para estimar valores de um atributo em locais não amostrados, a partir de pontos na mesma área ou região. O raciocínio base da interpolação é que os valores dos atributos tendem a ser similares em locais mais próximos do que em locais mais afastados (JAKOB; YOUNG, 2006).

Os métodos de interpolação são utilizados com o intuito de avaliar a variabilidade espacial de um atributo, baseado em dados situados em uma determinada área de estudo. Eles possibilitam projetar a relação espacial de um conjunto de dados e, assim, obter superfícies contínuas, representativas de fenômenos com distribuição espacial. (PERIN et. al., 2015; GARDIMAN JUNIOR et. al., 2012).

Dentre os diversos métodos de interpolação, utilizou-se a Ponderação do Inverso da Distância (IDW), a qual implementa o pressuposto de que pontos próximos possuem valores similares, enquanto que os pontos distantes são independentes e menos parecidos com os próximos. O IDW usa os valores amostrados à sua volta, que terão um maior peso do que os valores mais distantes, diminuindo esse peso com o aumento da distância. Por esse motivo, o IDW é bastante utilizado em mapas pluviométricos. Ele é um método exato, pois poucas decisões são tomadas acerca dos parâmetros do modelo (JAKOB; YOUNG, 2006).

Um dos motivos da escolha do IDW se deu em decorrência da análise dos pontos, uma vez que os pontos mais próximos da área de análise interpolada 
possuem maior influência do que os pontos distantes. Assim, os postos pluviométricos localizados dentro do território de Guaiúba detêm maior peso no total de precipitação da área de estudo, enquanto que os mais distantes não possuem a mesma importância, mas são essenciais na criação e análise das classes.

O IDW foi utilizado para gerar o mapa pluviométrico acumulado em função dos índices de vegetação. Um dos motivos disso foi o auxílio na interpretação da espacialização da cobertura vegetal. Através do mapa, é possível perceber círculos ao redor dos pontos amostrados. Segundo Righi e Basso (2016), essa tendência é explicada pelo caráter estatístico do método, cuja influência de cada ponto tende a ter um raio de ação definido em todas as direções.

Para a realização da interpolação foi utilizado o programa QGIS 2.18, através de sua ferramenta: raster $\rightarrow$ interpolação. Logo após, foi definida a extensão do município de Guaiúba. É nesse último procedimento que os postos pluviométricos inseridos dentro do território municipal detêm maior peso na espacialização da pluviometria.

Através do IDW, foi possível obter uma boa distribuição espacial das chuvas. Para isso, foram utilizados os dados de precipitação mensal do ano de 2019 até o mês de junho, data em que foram realizadas as análises dos índices de vegetação. No total, foram 12 postos pluviométricos utilizados para a análise. Através de seus dados mensais, foi gerado o total da precipitação, e este dado, interpolado.

\section{Resultados e Discussão}

\section{Índices de Vegetação}

Os Índices de Vegetação (IV) são medidas radiométricas adimensionais, que indicam a abundância relativa e a atividade da vegetação verde. Os mais empregados utilizam os dados das reflectâncias de dosséis referentes às regiões do vermelho e do infravermelho próximo, os quais são combinados (PONZONI, 2001).

Esses são uma combinação matemática a partir de diferentes bandas espectrais que mensuram a atividade da vegetação e sua variação sazonal. Assim, a partir do sinal eletromagnético absorvido ou refletido pela presença ou ausência da vegetação, há modificação na geração do índice, tendo em vista que quanto mais densa a cobertura vegetal menor será sua reflectância. Com isso, pode-se ter uma 
noção das áreas onde estão presentes o maior número de coberturas vegetais (PONZONI; SHIMABUKURO; KUPLICH, 2012).

Os índices de vegetação são modelos resultantes da combinação das bandas do vermelho e do infravermelho próximo. Segundo Jensen (2009), a combinação da reflectância de objetos da superfície em dois ou mais comprimentos de ondas desses canais é chamada de índice de vegetação. De acordo com Rosa (2007), as bandas do vermelho e do infravermelho próximo são mais utilizadas, justamente por obterem mais de $90 \%$ da resposta espectral da vegetação.

Vale ressaltar que grande parte dos processos existentes no comportamento espectral da vegetação ocorrem diretamente sobre uma folha. A escala de estudo adotada leva em consideração as relações existentes no dossel da vegetação. Entretanto, segundo Moreira (2005) apud Rocha (2016), o dossel pode ser compreendido como uma estrutura composta pela sobreposição de folhas, e sua arquitetura varia de acordo com os padrões fisionômicos de cada unidade fitoecológica. Dessa forma, o comportamento espectral do dossel vegetal apresenta similaridade com os modelos isolados das folhas.

Uma vez que a folha é o principal elemento da vegetação sob o ponto de
vista do processo de interação com a REM, muito do que foi discutido sobre
as características de reflectância das folhas, também é válido para os
dosséis. De fato, quando as curvas de reflectância de uma folha verde sadia
são comparadas com as medições espectrais de dosséis, apresentam
formas muito semelhantes. Essa semelhança permite que os padrões de
reflectância, apresentados pelos dosséis vegetais em imagens
multiespectrais, possam ser previstos, exatamente, de acordo com o padrão
de reflectância (PONZONI, 2001, p. 178).

Todas essas características são importantes para a geração e para a compreensão dos índices de vegetação, os quais são primordiais para compreender o estado de conservação da vegetação de estudo.

A partir disso, os índices utilizados para a realização deste trabalho foram: Índice de Vegetação por Diferença Normalizada (NDVI) e o Índice de Vegetação Ajustado ao Solo (SAVI).

O NDVI é a razão entre a diferença de reflectividade das bandas no infravermelho próximo e no vermelho e pela soma dessas mesmas. O NDVI é um indicador da quantidade e condição da vegetação, cujos valores variam no intervalo de -1 a 1.

Desta forma, sua fórmula consiste em:

$$
N D V I=N I R-V E R / N I R+V E R
$$

Assim: 
Os tons de cinza mais claros estão relacionados aos valores mais elevados de NDVI, enquanto os mais escuros, aos valores mais baixos. Os valores mais elevados estão relacionados às áreas com maior quantidade de vegetação fotossinteticamente ativa, enquanto os mais escuros representam as áreas com menor quantidade de vegetação (PONZONI; SHIMABUKURO; KUPLICH, 2012, p. 91).

O Índice de Vegetação Ajustado ao Solo (SAVI), segundo Jensen (2009), é um índice que leva em consideração efeitos do solo exposto ao considerar a incorporação de um fator de ajuste dependente da densidade de vegetação. $O$ índice SAVI enfatiza a influência de solo exposto, especialmente no período seco quando a vegetação de caatinga perde suas folhas. $O L$ é um fator de ajuste para o substrato do dossel, podendo assumir valores de 0 a 1 a depender da cobertura do solo. Dessa forma, destacam-se bem as áreas que apresentam solos expostos e pouca vegetação.

Para o cálculo desse índice, utiliza-se a seguinte fórmula:

$$
\mathrm{SAVI}=(1+\mathrm{L}){ }^{*}(\mathrm{NIR}-\mathrm{VER}) / \mathrm{NIR}+\mathrm{VER}+\mathrm{L}
$$

Ambos utilizam a radiância do Infravermelho Próximo (NIR) e do Vermelho (VER). Esses índices são empregados como indicadores do crescimento e do vigor da vegetação e podem ser utilizados no diagnóstico de vários parâmetros biofísicos (PONZONI, 2001).

\section{Análise pluviométrica e aplicação dos Índices de Vegetação na discussão da atividade vegetacional}

Para a análise da precipitação, foram escolhidos 10 postos pluviométricos em torno da área em estudo e dois postos do município em questão, totalizando 12 postos (Figura 1). A escolha deles se deu em função de sua influência direta nos totais pluviométricos de Guaiúba. Em decorrência disso, os postos pluviométricos escolhidos foram: Horizonte, Palmácia, Redenção, Guaiúba, Itacima (Guaiúba), Olho d'água (Maranguape), Itaipaba (Pacajus), São Gerardo (Redenção), Acarape, Pacatuba e dois em Itaitinga. 
Figura 1 - Espacialização dos postos pluviométricos

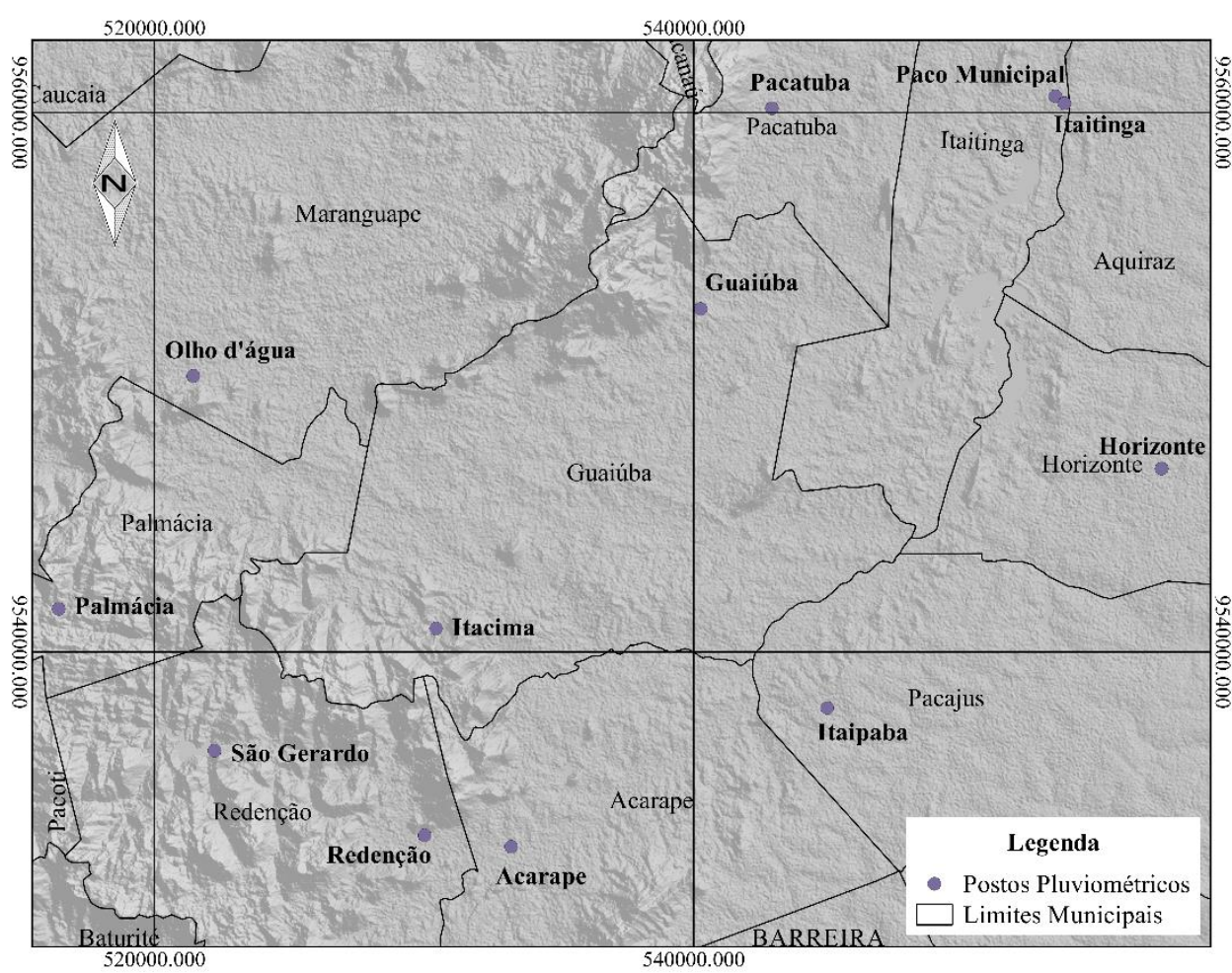

Fonte: FUNCEME (2019), IBGE (2017), Alos Palsar (2011). Org.: Elaborada pelo autor.

Os totais pluviométricos foram analisados até o mês das imagens de satélite, uma vez que os dados da cobertura vegetal e das taxas de precipitação se interligam. Assim, os dados foram interpretados de janeiro até junho de 2019, como se pode ver na (Tabela 1).

A escolha desse intervalo ocorreu em razão da detecção da atividade fotossintética pelos índices de vegetação. Assim, foi analisado o mês de junho por ainda apresentar atividade vegetativa, tendo em vista que, somente a partir do final de julho e começo de agosto que a vegetação de caatinga perde suas folhas.

Tabela 1 - Precipitação (mm) mensal acumulada de 2019

\begin{tabular}{|c|c|c|c|c|c|c|c|c|}
\hline Posto & Jan & Fev & Mar & Abr & Maio & Jun & Total & Média \\
\hline Redenção & 140,6 & 219 & 288 & 216,5 & 124,2 & 56 & 1044,3 & 174,05 \\
\hline Itacima & 99 & 285 & 346 & 261 & 96 & 62 & 1149 & 191,5 \\
\hline São Gerardo & 154,4 & 274,1 & 286,2 & 200,5 & 144,4 & 83 & 1142,1 & 190,35 \\
\hline Guaiúba & 76 & 387 & 355 & 283 & 214 & 70 & 1385 & 230,83 \\
\hline Itaipaba & 184 & 179 & 239 & 130 & 101 & 30 & 863 & 143,83 \\
\hline Acarape & 123 & 230 & 286 & 184 & 115 & 44 & 982 & 163,66 \\
\hline Palmácia & 236,2 & 293,5 & 498,8 & 233,4 & 200,8 & 109 & 1571,3 & 261,88 \\
\hline Pacatuba & 84,9 & 293,2 & 295,4 & 370,7 & 138,6 & 72 & 1254,9 & 209,15 \\
\hline Olho d'água & 155,6 & 254,2 & 318,4 & 152,8 & 155,5 & 62 & 1098,2 & 183,03 \\
\hline Itaitinga & 166 & 243 & 592 & 456 & 213,5 & 88 & 1758,5 & 293,08 \\
\hline Paço & 92 & 233 & 632 & 443,5 & 184 & 77 & 1661,5 & 276,91 \\
\hline
\end{tabular}




\begin{tabular}{|c|c|c|c|c|c|c|c|c|}
\hline Municipal & & & & & & & & \\
\hline Horizonte & 327,1 & 307 & 448,5 & 327,3 & 194,5 & 43 & 1646,9 & 274,48 \\
\hline Total & 1838,8 & 3198 & 4585,3 & 3258,7 & 1881,5 & 794 & - & - \\
\hline
\end{tabular}

Fonte: FUNCEME (2019). Org.: Elaborada pelo autor.

Em todos os postos, destacam-se, principalmente, os meses de fevereiro, março e abril, que perfazem o período chuvoso da região. Logo após essa fase, as médias declinam e já apresentam índices mais baixos em junho. Nesse ano, o mês que mais choveu foi março, atingindo o total de 4585,3 mm, seguido por abril, fevereiro, maio, janeiro e junho.

Nota-se que a maior média pluviométrica ocorreu no posto de Itaitinga, seguido pelo outro posto de Itaitinga, Horizonte e Pacatuba. Devido à distância e à localização desses postos em relação ao município de Guaiúba, pode-se compreender a direção das chuvas e de seu decréscimo em direção ao interior do Estado do Ceará.

O maior índice registrado de pluviometria foi em março pelo posto do Paço Municipal de Itaitinga, e o menor ocorreu no mês de junho no distrito de Itaipaba. No tocante aos valores totais, o posto de Itaitinga apresentou os maiores índices, e Itaipaba, os menores. Nesse sentido, há concentração maior de precipitação nos municípios de Itaitinga e Horizonte, enquanto que, em Pacajus, seu valor decresce fortemente, totalizando a diferença de $895,5 \mathrm{~mm}$.

Em relação aos dados dos postos da área em estudo, o posto de Guaiúba apresentou os maiores valores mensais, destacando-se o mês de fevereiro, com 387 $\mathrm{mm}$ e, em Itacima, o mês de março, com $346 \mathrm{~mm}$. Em ambos os postos, os meses que concentraram as chuvas foram fevereiro, março e abril. No tocante aos valores totais, o posto de Guaiúba alcançou $1385 \mathrm{~mm}$, e Itacima, $1149 \mathrm{~mm}$. Essa diferença demonstra o decréscimo das taxas de precipitação em relação ao sul do município.

Com base no Mapa 2 e na Tabela 1, pode-se perceber que os menores valores totais e de suas médias são dos postos de Pacajus e Acarape. Dessa forma, apresentam-se no mapa os menores valores das isoietas e das classes de precipitação em direção a esses municípios. Na direção sul e sudeste de Guaiúba, são registradas as mais baixas taxas, enquanto que, na porção norte, por influência da elevada precipitação do posto Guaiúba e dos postos de Pacatuba e Itaitinga, os valores das classes são mais elevados.

O mapa pluviométrico, por ser gerado através de interpolação, está diretamente relacionado à posição dos postos pluviométricos. Assim, nos mapas, a 
espacialização da pluviometria é influenciada pela distância entre os postos e seu total de chuvas. Nesse sentido, devido à distância para a área em estudo, o posto Guaiúba e Itacima se apresentam como os mais importantes para a compreensão da dinâmica das chuvas.

Vale destacar que o valor mais baixo interpolado de precipitação foi 982,2 mm, e o mais alto atingiu 1403,2 mm. Levando em consideração a média dos últimos 40 anos de precipitação $(1009,9 \mathrm{~mm})$, ambos os valores, mesmo sendo analisados nos primeiros 6 meses do ano, apresentam bom índice de precipitação em uma região comandada pelo clima semiárido.

Mapa 2 - Pluviometria acumulada (06/2019) no município de Guaiúba/CE

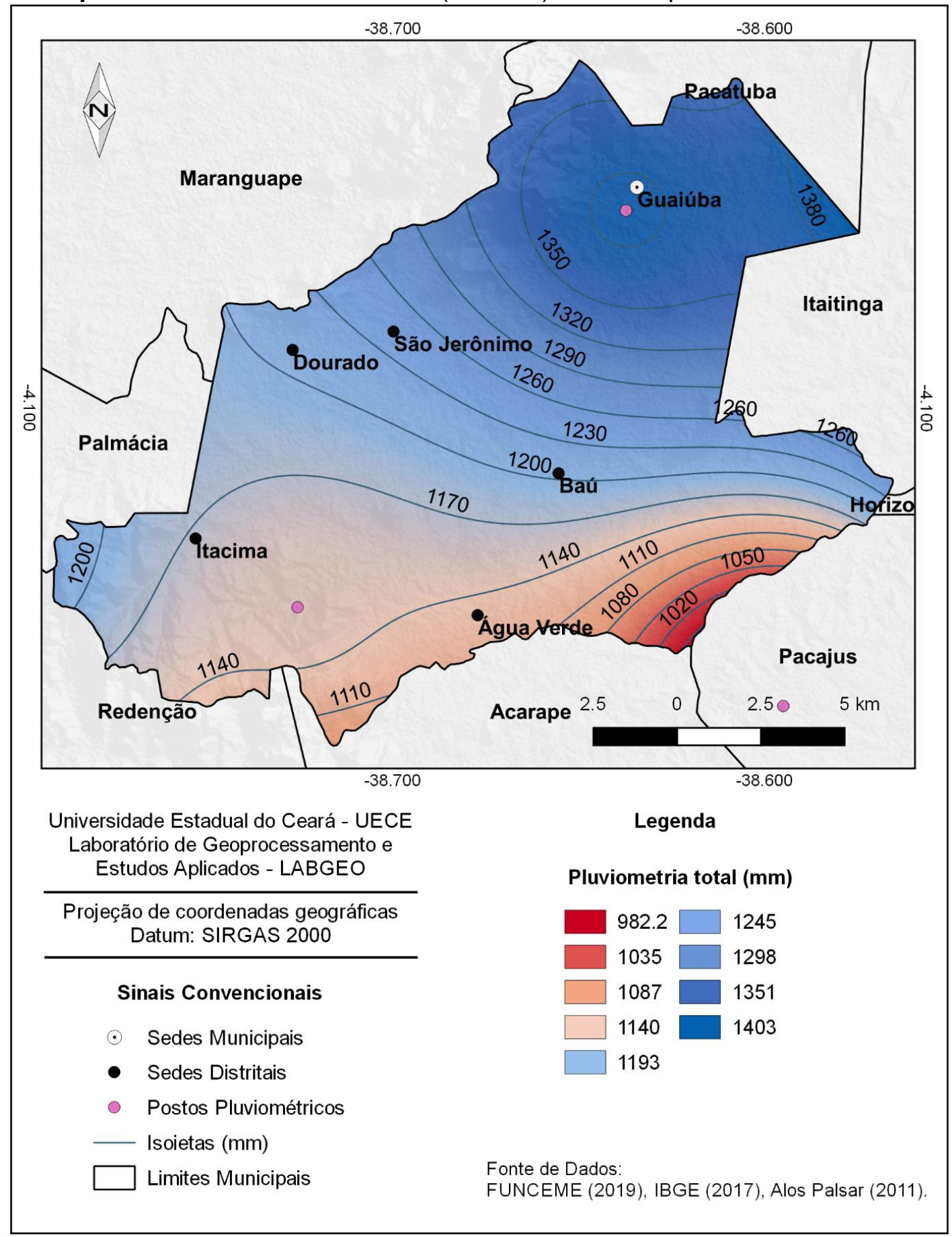


Outra característica marcante na área de estudo é a irregularidade das chuvas. Após o final do período chuvoso, não há praticamente geração de precipitação, fazendo com que a atividade fotossintética se concentre nos meses iniciais do ano. Assim, devido à baixa absorção de água pela vegetação predominante de caatinga, principalmente após o mês de junho, a banda 5 do infravermelho próximo, que já absorve pouca água, torna a reflectância praticamente constante.

Em todos os postos, o mês de junho apresenta baixos índices de pluviometria, o que se deve ao fim do período chuvoso, que termina em maio. Após o final do mês de junho, a vegetação apresenta menores índices fotossintéticos.

Ainda em relação ao mapa pluviométrico, suas classes geradas através do IDW representam bem a distribuição da precipitação. Ao norte de Guaiúba, há um elevado relevo, o qual compreende o Maciço Residual da Aratanha. O município em estudo situa-se na vertente úmida desse relevo, onde há elevados índices de precipitação, frutos de suas características de exceção.

De acordo com Souza e Oliveira (2006), essas áreas de exceção, em geral, concentram melhores condições ambientais e componentes naturais nos planos climático, pedológico e hidrológico. Devido aos seus elevados níveis altimétricos, o Maciço da Aratanha e de Baturité configuram-se como áreas de exceção em relação à região semiárida, que, associada à sua orientação e à proximidade do litoral, acaba favorecendo o recebimento de ventos oriundos do mar, que condicionam a formação de chuvas orográficas nas vertentes situadas à barlavento (BRANDÃO, 1998; SOUZA, 2011).

Em direção ao sudoeste do município, há outro ambiente de exceção, que compreende o Maciço Residual de Baturité, cuja dimensão no território cearense faz com que esse relevo seja o maior Maciço úmido do Ceará. Esses dois ambientes e a proximidade com o litoral influenciam diretamente os índices de precipitação da área em estudo, contudo vale ressaltar que, para o município de Guaiúba, o Maciço de Baturité não alcança seus maiores níveis de altitude.

Dessa forma, há de se considerar a proximidade com o litoral, direção dos ventos e a altitude dos relevos, pois esses fatores influenciam na ascensão das massas de ar, uma vez que, quando elas são carregadas de umidade, o ar mais quente encontra a barreira natural e se eleva ocorrendo a condensação do vapor e, posteriormente, gerando chuvas (ZANELLA; SALES, 2011). 
Essas características combinadas com as dos demais componentes ambientais e as formas de uso e ocupação do solo interferem diretamente na dinâmica da vegetação. Enquanto que os processos naturais causam maior influência na formação das unidades fitoecológicas, as atividades socioeconômicas agem principalmente nas mudanças de seu equilíbrio natural, modificando sua quantidade, fundamentalmente, por meio de queimadas e desmatamentos (Figura 2), substituição das espécies nativas por exóticas, além de modificações na sua própria estrutura.

Figura 2 - Uso recorrente de queimadas e desmatamentos

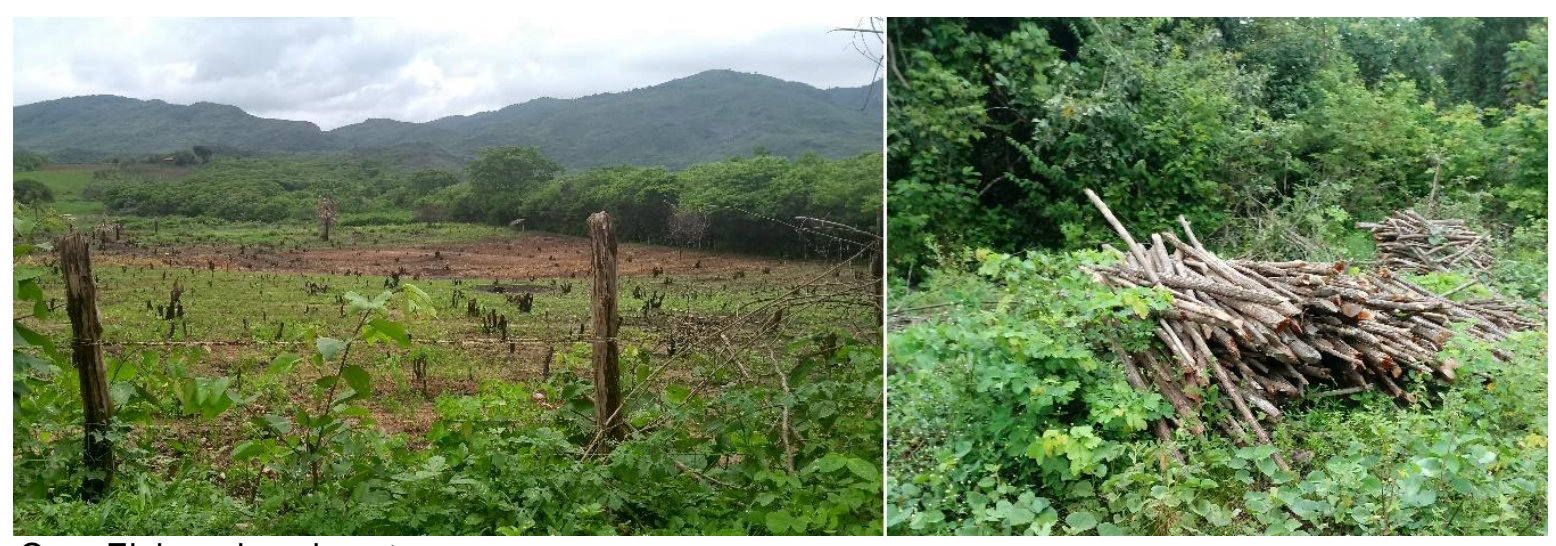

Org.: Elaborada pelo autor.

As características ambientais dos relevos de Guaiúba juntamente com os aspectos climáticos agem diretamente na distribuição da vegetação. Nos ambientes com as menores altitudes há predomínio da vegetação da caatinga, em direção aos maciços este quadro natural se modifica. Uma vez que, as diferenças altitudinais e a forma do relevo, a quantidade de umidade, a espessura dos solos e a temperatura, influenciam diretamente nos tipos de vegetação.

Segundo a Superintendência Estadual do Meio Ambiente (2010), a caatinga (Figura 3) normalmente ocupa a base e os níveis altimétricos mais baixos. Possui uma fisionomia arbustiva com a presença de algumas espécies arbóreas. A mata úmida (Figura 4) abrange as áreas mais úmidas das serras, abrangendo as altitudes superiores a 500-600 metros. E a mata seca preenche preferencialmente as áreas altimétricas acima da vegetação da caatinga até 500-600 metros e abaixo da mata úmida, caracteriza-se por uma vegetação de transição. 
Figura 3 - Vegetação de Caatinga em Guaiúba

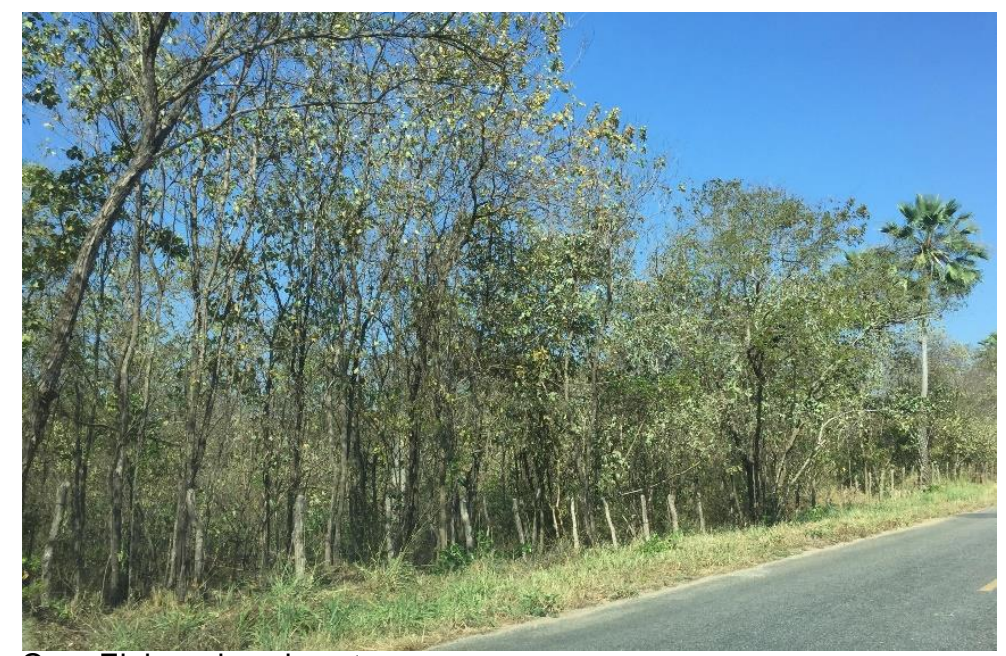

Org.: Elaborado pelo autor.

Figura 4 - Vegetação de Mata Plúvio-Nebular do Maciço da Aratanha

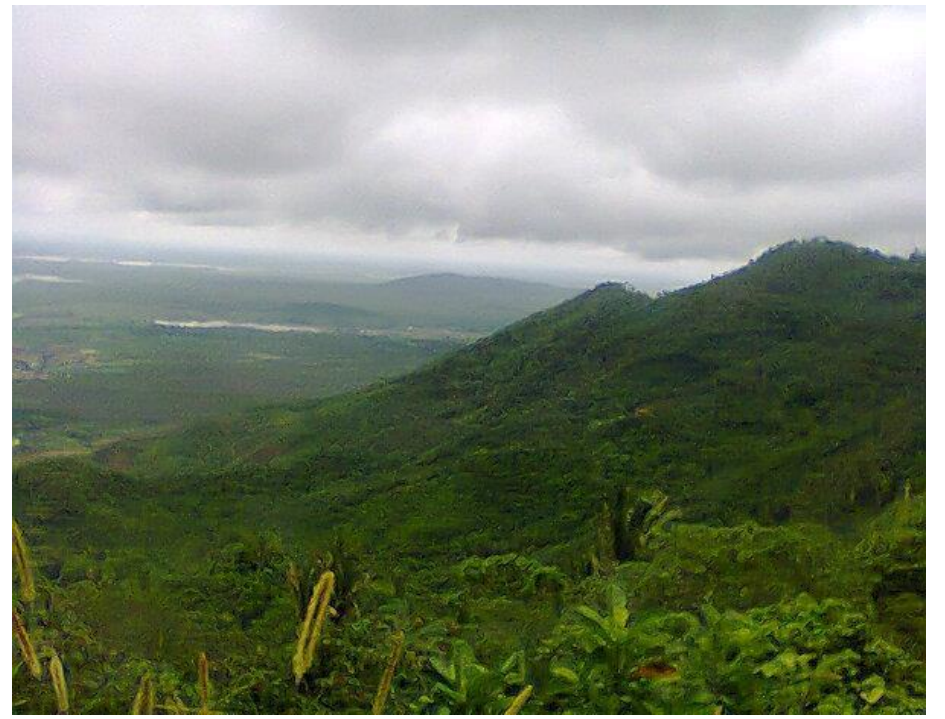

Org.: Elaborado pelo autor.

Através dos índices de vegetação, é possível avaliar alguns desses aspectos levantados, principalmente no tocante à espacialização da vegetação, sua concentração e sua atividade fotossintética.

Com base na geração desses índices, foram criadas classes no intuito de detectar e analisar a atividade da vegetação. As classes geradas estão relacionadas à capacidade de absorção, reflectância e transmitância da REM pelos dosséis, são elas: baixa, moderadamente baixa, média, moderadamente alta e alta. Essas cinco divisões expressam as características dos dosséis detectados, além de sua associação com outras classes, especialmente os solos expostos.

Nos dois índices, as mesmas bandas são utilizadas: banda 4 (vermelho) e banda 8 (infravermelho próximo) para a sua geração. Dentro da região do visível, encontra-se o canal do vermelho. A baixa reflectância das folhas nessa região é 
decorrente da absorção da radiação solar pelos pigmentos fotossintetizantes. $\mathrm{Na}$ região do infravermelho próximo, há pequena absorção e alta reflectância da atividade fotossintética, devido principalmente aos espaços existentes na estrutura interna das folhas. Quanto maior forem as lacunas, maior será os valores de reflectância (PONZONI; SHIMABUKURO; KUPLICH, 2012; PONZONI, 2001).

Nos Mapas 3 e 4, quando os dosséis apresentam cor escura, esse fato se explica em função da absorção dos pigmentos fotossintetizantes, como também das sombras geradas pelos próprios dosséis. Em razão disso, há baixa reflectância da REM. A situação é semelhante em relação ao número de água na estrutura interna das folhas, pois quanto maior sua quantidade, menor será sua capacidade refletida (PONZONI; SHIMABUKURO; KUPLICH, 2012; PONZONI, 2001).

Já em casos de dosséis esparsos, é importante destacar a função dos solos em absorver a REM. Isso fica mais explícito no mapa do SAVI. Tanto para as folhas como para os dosséis, a reflectância é semelhante.

De modo geral, quanto mais exposto for o solo, maiores serão os valores de reflectância no canal do visível. Nessa região, os solos mais claros exercem maior influência na reflectância por não absorverem tanta radiação. No canal do infravermelho próximo, há maior reflectância com o aumento da biomassa em áreas ocupadas pelos solos mais escuros, enquanto que, nos mais claros, verifica-se diminuição da reflectância. Geralmente, na região do infravermelho próximo, os efeitos são inversos quando comparados ao canal do visível. Isso ocorre devido ao espalhamento (reflexão e transmitância) múltiplo entre as camadas de folhas dispostas no dossel (PONZONI, 2001).

As características de absorção e reflectância da vegetação torna-se essencial para compreender sua dinâmica e seus demais fatores mesológicos. Nas áreas mais elevadas, principalmente com o NDVI, pode-se notar que a vegetação assume tonalidade mais escura, devido à presença de água, sombras e a estrutura dos dosséis. $O$ canal do infravermelho na banda 5 influencia diretamente nessa relação. Segundo Ponzoni (2001), nessa região, a água existente no interior das células ou em lacunas é a grande responsável pela maioria de absorção. Caso semelhante ocorre com os pigmentos fotossintetizantes no canal do visível. 
Mapa 3 - Índice de Vegetação SAVI (28/06/2019) no município de Guaiúba/CE

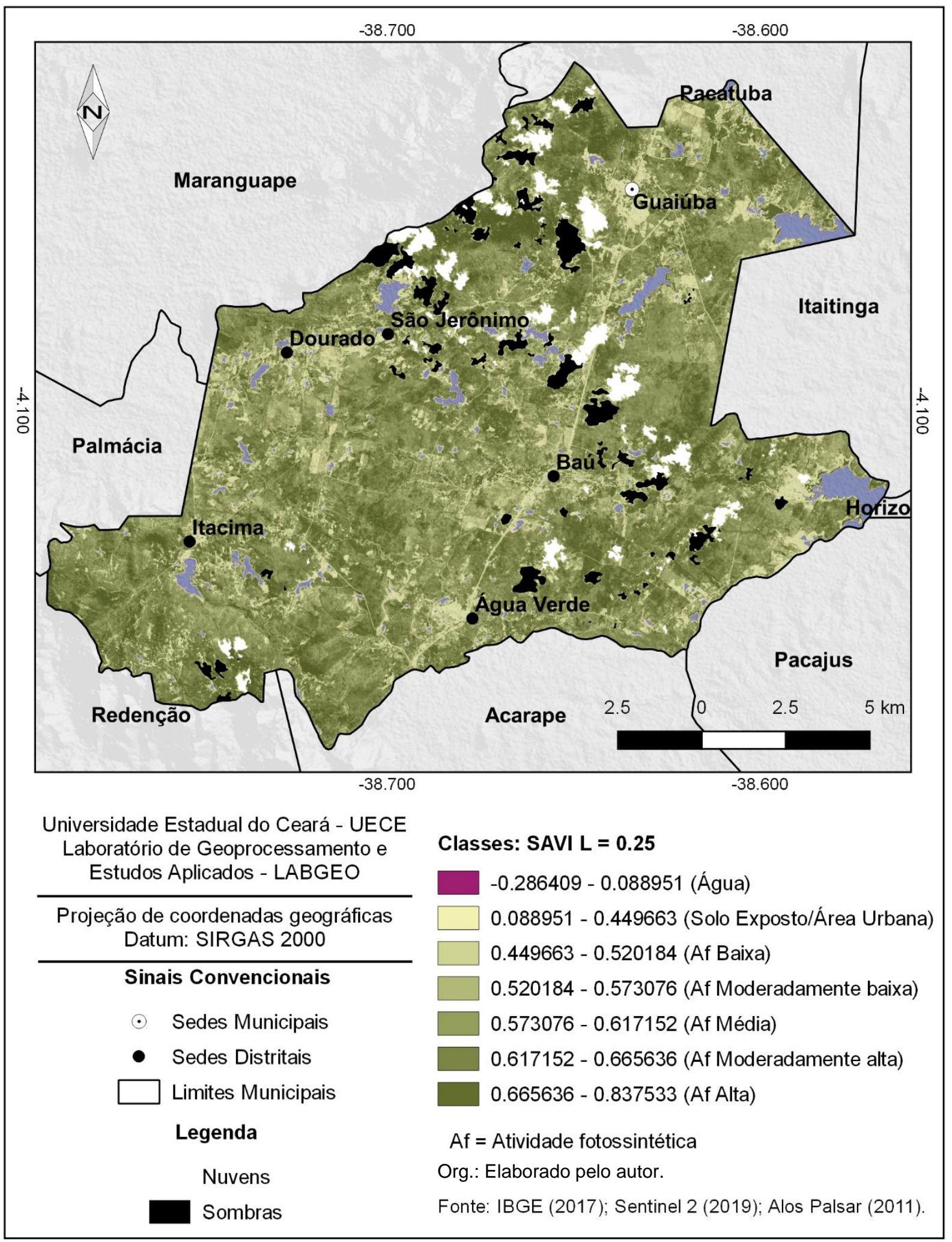


Mapa 4 - Índice de Vegetação NDVI (28/06/2019) no município de Guaiúba/CE

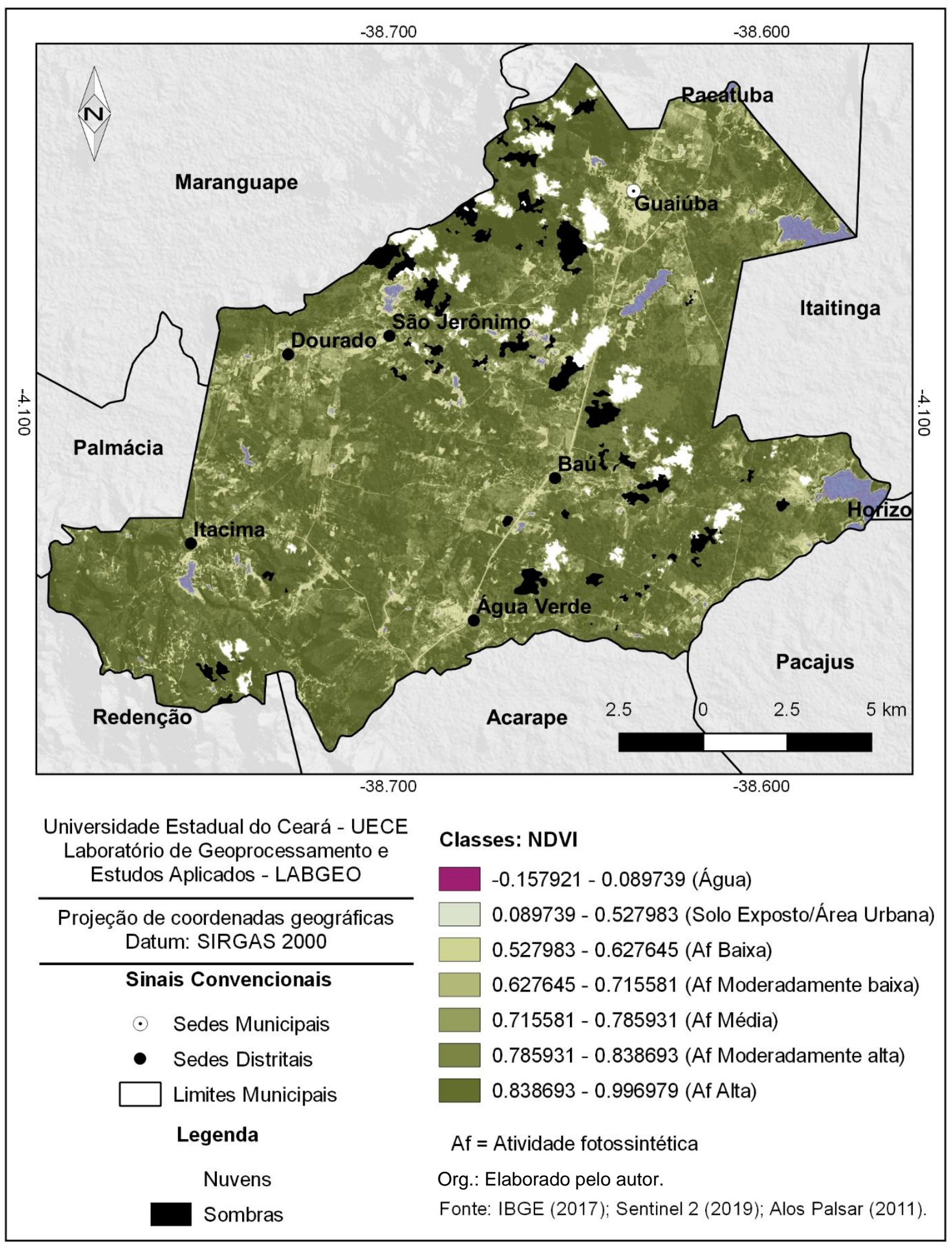

Como já mencionado, os dois índices utilizados no trabalho foram o NDVI e o SAVI 0.25. A escolha desse fator se deu por apresentar os melhores resultados do SAVI na área em estudo. 
Devido ao fator de ajuste do solo existente no SAVI, o mapa que expressa esse índice de vegetação apresentou os melhores resultados de atividade fotossintética na depressão sertaneja, principalmente porque as maiores áreas de solo exposto se encontram nesse sistema ambiental. Para as áreas mais elevadas, o índice NDVI expressou melhor a atividade da vegetação de mata úmida nos maciços. Isso se deve à grande quantidade de dosséis, aos pigmentos fotossintetizantes e à significativa presença de umidade na vegetação, fazendo com que a absorção seja maior e seus valores, mais elevados. Esse mesmo fato serve para o SAVI, entretanto sua quantidade de área detectada foi menor (Tabela 2).

Tabela 2 - Classes temáticas e quantidade de área dos índices de vegetação

\begin{tabular}{ccccc}
\hline \multirow{2}{*}{ Classes } & \multicolumn{2}{c}{ SAVI 025 } & \multicolumn{2}{c}{ NDVI } \\
\cline { 2 - 5 } & $\begin{array}{c}\text { Área } \\
\mathrm{km}^{2}\end{array}$ & $\begin{array}{c}\% \text { área } \\
\text { total }\end{array}$ & $\begin{array}{c}\text { Área } \\
\mathrm{km}^{2}\end{array}$ & $\begin{array}{c}\% \text { área } \\
\text { total }\end{array}$ \\
\hline Corpos Hídricos & 7,747 & 2,9 & 4,346 & 1,6 \\
\hline $\begin{array}{c}\text { Solo Exposto/Área Urbana } \\
\text { Atividade fotossintética } \\
\text { baixa }\end{array}$ & 19,517 & 8 & 13,051 & 4,8 \\
\hline $\begin{array}{c}\text { Atividade fotossintética } \\
\text { moderadamente baixa }\end{array}$ & 38,258 & 7,3 & 8,999 & 3,3 \\
\hline $\begin{array}{c}\text { Atividade fotossintética } \\
\text { média }\end{array}$ & 66,993 & 25,1 & 29,244 & 10,9 \\
\hline $\begin{array}{c}\text { Atividade fotossintética } \\
\text { moderadamente alta }\end{array}$ & 65,912 & 24,6 & 65,993 & 24,7 \\
\hline $\begin{array}{c}\text { Atividade fotossintética } \\
\text { alta }\end{array}$ & 31,67 & 11,8 & 112,256 & 42 \\
\hline Nuvens & 7,138 & 2,67 & 7,138 & 2,67 \\
\hline Sombras & 8,028 & 3 & 8,028 & 3 \\
\hline
\end{tabular}

Org.: Elaborada pelo autor.

Com base na Tabela 2 e nos Mapas 3 e 4, é possível perceber que a quantidade de corpos hídricos é menor em relação ao NDVI. Esse índice não apresentou um bom resultado na quantificação dessa classe e, em muitas áreas, houve confusão com solo exposto. Já o SAVI apresentou a quantidade de corpos hídricos mais próxima da realidade.

Em relação aos solos expostos e área urbana, essa associação ocorre devido à resposta espectral de seus alvos serem próximas. O SAVI continua com a maior área quantificada, devido ao seu fator de ajuste ao solo (L). A escolha do 0.25 se deu em razão da grande área de vegetação no município de Guaiúba, enquanto que o fator 1 é indicado para áreas com pouca cobertura vegetal. Em ambos os índices, a maior quantidade de solos expostos ocorre na depressão sertaneja, fruto 
principalmente da intensa atividade de retirada da vegetação para moradias, vias, pecuária e agricultura.

No tocante às classes de atividade fotossintética, elas são o centro da discussão, uma vez que o objetivo dos índices de vegetação é quantificar esse tipo de atividade. Em relação à atividade fotossintética baixa, o SAVI identificou bem mais que o NDVI: a diferença passa de $10 \mathrm{~km}^{2}$. Nessa classe, há grande presença de cobertura vegetal muito rala, com espécies de porte baixo associada aos solos expostos. Em ambos os mapas, essa classe ocorre principalmente na depressão sertaneja e nas planícies fluviais próximas de áreas urbanas, corpos hídricos, locais de lavouras e pecuária, ambientes onde há uso intenso da vegetação.

A classe moderadamente baixa, que possui cobertura vegetal rala em alguns ambientes com traços de aberta e espécies de baixo a médio porte, está menos associada aos solos expostos que a classe de atividade fotossintética baixa. Há também áreas de lavouras que expressam ambientes com uso. Novamente, 0 índice SAVI expressou uma maior quantidade de área dessa classe em relação ao NDVI, fato decorrente do fator de ajuste ao solo, que identificou melhor áreas onde a atividade fotossintética não é alta e que se relacionam aos solos expostos.

Em relação à classe de atividade fotossintética média, ela expressa traços de cobertura vegetal aberta com porte predominantemente subarbórea. Essas áreas, que apresentam uso, mas em menor escala em relação às classes com menor atividade, geralmente são ambientes com cobertura vegetal em recuperação. No índice SAVI, essa classe apresentou os maiores valores em área quantificada e se espalham por todo o território municipal. Ela expressa, ainda, a transição entre as classes baixas e altas de atividade fotossintética, bem como entre os ambientes de pouca a muita cobertura vegetal.

$\mathrm{Na}$ classe de atividade fotossintética moderadamente alta, há cobertura vegetal densa e vegetação subarbórea a arbórea. São ambientes que também apresentam condições de recuperação, mas é possível identificar áreas conservadas, principalmente em direção aos maciços. Em ambos os índices, a quantidade em área é praticamente a mesma, entretanto sua espacialização é diferente. Enquanto que no SAVI essa classe espraia-se por todo o território, no NDVI há bastante concentração na depressão sertaneja.

No tocante à classe de atividade fotossintética alta, há cobertura vegetal muito densa e vegetação de porte arbóreo em relação ao SAVI. No NDVI, ela é a classe com maior quantidade de área, totalizando $42 \%$ do município. Nesse índice, 
ocorre uma sobrevalorização e uma homogeneidade da área em estudo. Podem-se encontrar, ainda, parcelas de cobertura vegetal conservadas e sem formas diretas de uso.

As áreas com atividade fotossintética alta estão em grande parte localizadas no Maciço da Aratanha e de Baturité. Isso se deve ao fato da presença de vegetação arbórea e com cobertura densa. Nesses ambientes serranos da área de estudo, existem melhores condições ambientais e de componentes naturais nos planos climático, pedológico e hidrológico.

Nessa classe, o NDVI abordou melhor a vegetação nas áreas mais elevadas e com dosséis mais densos. Os valores altos se relacionam às áreas de vegetação com maior vigor. Quanto mais próximo de 1, mais densa é a vegetação. O 0, por sua vez, indica superfície inexistente de vegetação.

De modo geral, as classes geradas através do SAVI representam melhor a área em estudo. Apenas os maciços devem apresentar atividade fotossintética mais elevada como no NDVI. Assim, pode-se compreender que a utilização somente do SAVI não causaria interpretação tendenciosa da vegetação em relação a toda a área do município, enquanto que o NDVI identificou bastante área de atividade fotossintética alta não correspondendo à realidade, principalmente em relação à depressão sertaneja. A quantificação da atividade fotossintética através desses índices permite criar uma aproximação de quais áreas estão com seus dosséis sadios, orientando, assim, a identificação de coberturas vegetais conservadas e degradadas.

Em locais onde os dosséis não estão saudáveis, eles passam por efeitos de estresse, tais como: doenças, ataques de insetos, problemas fisiológicos, condições ambientais adversas, perda de proteínas etc. Há, também, mudanças no conteúdo dos pigmentos fotossintetizantes e, consequentemente, perda de clorofila, fazendo com que a reflectância aumente no canal do visível e seus valores sejam mais baixos (PONZONI, 2001).

\section{Considerações Finais}

O artigo apresentou uma discussão a respeito da aplicação dos índices de vegetação no reconhecimento e análise da atividade vegetacional. Para isso, realizou-se a análise pluviométrica da área de estudo juntamente com a aplicação do SAVI e do NDVI, os quais demonstraram resultados da atividade fotossintética, 
retratando o estado dos dosséis, os picos verdes da cobertura vegetal e sua espacialização.

Para o alcance do objetivo do artigo segmentou-se a metodologia em duas partes. Primeiramente foi tratada a respeito da geração dos índices de vegetação, em seguida houve a discussão e implementação do interpolador IDW para a produção e análise da pluviometria de Guaiúba.

Os resultados e as discussões geradas estão diretamente relacionadas a análise pluviométrica e as classes criadas através do índices de vegetação. Essas classes foram formadas principalmente em relação à capacidade de absorção, reflectância e transmitância da REM pelos dosséis. Assim, foram criados intervalos que dividem a atividade fotossintética em 5 classes, são elas: baixa, moderadamente baixa, média, moderadamente alta e alta. Essas divisões expressam as características dos dosséis detectados, além de sua associação com outras classes, especialmente os solos expostos.

Essas classes expressam as diferentes formas de uso da terra em Guaiúba. Na classe com atividade fotossintética baixa há grande presença de cobertura vegetal muito rala, com espécies de porte baixo associada aos solos expostos. Na classe moderadamente baixa, há cobertura vegetal rala em alguns ambientes com traços de aberta e espécies de baixo a médio porte, está menos associada aos solos expostos que a classe de atividade fotossintética baixa.

Em relação à classe de atividade fotossintética média, ela expressa traços de cobertura vegetal aberta com porte predominantemente subarbórea. Essas áreas, que apresentam uso, mas em menor escala em relação às classes com menor atividade, geralmente são ambientes com cobertura vegetal em recuperação. $\mathrm{Na}$ classe de atividade fotossintética moderadamente alta, há cobertura vegetal densa e vegetação subarbórea a arbórea. São ambientes que também apresentam condições de recuperação, mas é possível identificar áreas conservadas, principalmente em direção aos maciços.

No tocante à classe de atividade fotossintética alta, há cobertura vegetal muito densa e vegetação de porte arbóreo. As áreas com atividade fotossintética alta estão em grande parte localizadas no Maciço da Aratanha e de Baturité. Isso se deve ao fato da presença de vegetação arbórea e com cobertura densa.

Através das discussões e dos resultados levantados foi possível demonstrar a análise pluviométrica acumulada do município de Guaiúba. Além da quantificação das classes de atividade fotossintética geradas pelos índices de 
vegetação. No geral, o índice SAVI expressou os melhores resultados para compreender a realidade da cobertura vegetal local.

Vale ressaltar que os resultados gerados possuem grande relevância para a poder municipal, uma vez que, os mesmos demonstram a quantidade de áreas com solo exposto e a atividade da vegetação frente diversas formas de uso da terra. Nesse sentido, políticas ambientais podem ser realizadas com o objetivo de fiscalizar e diminuir esses espaços sem vegetação. Além de gerar bases para um planejamento ambiental através da análise da cobertura vegetal.

\section{Referências Bibliográficas}

BRANDÃO. R. L. Diagnóstico geoambiental e os principais problemas de ocupação do meio físico da região metropolitana de Fortaleza. Fortaleza: CPRM, 1998.

SUPERINTENDÊNCIA ESTADUAL DO MEIO AMBIENTE. Área de Proteção Ambiental da Serra da Aratanha. Fortaleza, 03 mar. 2020. Página eletrônica: SEMACE. Disponível em: http://www.semace.ce-.gov.br/2010/- 12/area-de-protecao-ambiental-da-serra-da-aratanha/. Acesso em: 03 mar. 2020.

INSTITUTO BRASILEIRO DE GEOGRAFIA E ESTATÍSTICA. Cidades e Estados. Rio de Janeiro, 8 abr. 2020. Página eletrônica: IBGE. Disponível em: IBGE -

https://www.ibge.gov.br/cidades-e-estados/ce/guaiuba.html. Acesso em: 8 abr. 2020.

JENSEN, J. R. Sensoriamento remoto do ambiente: uma perspectiva em recursos terrestres. São Paulo: Editora Parêntese, 2009.

JAKOB, A. A. E.; YOUNG, A. F. O uso de métodos de interpolação espacial de dados nas análises sociodemográficas. ENCONTRO NACIONAL DE ESTUDOS POPULACIONAIS, 15, 2006, Caxambu. Anais... Caxambu: ENEP, 2006.

PERIN, E. B. et. al. Interpolação das variáveis climáticas temperatura do ar e precipitação: revisão dos métodos mais eficientes. GEOgraphia, Santa Catarina, v. 40, n. 2, 2015.

PONZONI, F. J. Comportamento espectral da vegetação. In: MENESES, P. R.; MADEIRA NETTO, J. S. (Org.). Sensoriamento remoto: reflectância dos alvos naturais. Brasília: UnB, 2001, p. 157-189.

PONZONI, F. J.; SHIMABUKURO, Y. E.; KUPLICH, T. M. Sensoriamento remoto da vegetação. 2. ed. São Paulo: Oficina de Textos, 2012.

ROCHA, N. M. Avaliação dos índices NDVI e SAVI para caatinga do Seridó Ocidental do Estado da Paraíba. 2016. 59f. Monografia (Graduação em Geografia) - Universidade Estadual do Ceará, Fortaleza, 2016.

ROSA, R. Introdução ao sensoriamento remoto. Uberlândia: EDUFU, 2007.

SOUZA, M. J. N.; OLIVEIRA, V. P. V. Os enclaves úmidos e sub-úmidos do semiárido do Nordeste brasileiro. Mercator, Fortaleza, n. 9, 2006. 
SOUZA, M. J. N. Contexto ambiental do enclave úmido da Serra de Baturité - Ceará. In: BASTOS, F. H. B. (Org.). Serra de Baturité: uma visão integrada das questões ambientais. Fortaleza: Expressão Gráfica e Editora, 2011. p. 19-33.

ZANELLA, M. E.; SALES, M. C. L. Considerações sobre o clima e a hidrografia do Maciço de Baturité. In: BASTOS, F. H. B. (Org.). Serra de Baturité: uma visão integrada das questões ambientais. Fortaleza: Expressão Gráfica e Editora, 2011. p. 61-75.

ZULLO JUNIOR, J. Correção atmosférica de imagens de satélites e aplicações. 1994. 203f. (Doutorado em Engenharia Elétrica) - Programa de Pós-Graduação em Engenharia Elétrica, Universidade Estadual de Campinas, São Paulo, 1994.

\section{NOTAS DE AUTOR}

\section{CONTRIBUIÇÃO DE AUTORIA}

Túlio Viana Bandeira - Concepção. Coleta de dados, Análise de dados, Elaboração do manuscrito, Participação ativa da discussão dos resultados.

Maria Lúcia Brito da Cruz - Participação ativa da discussão dos resultados; Revisão e aprovação da versão final do trabalho.

\section{FINANCIAMENTO}

Coordenação de Aperfeiçoamento de Pessoal de Nível Superior (CAPES) na forma de bolsa.

\section{CONSENTIMENTO DE USO DE IMAGEM}

Não se aplica.

\section{APROVAÇÃO DE COMITÊ DE ÉTICA EM PESQUISA}

Não se aplica.

\section{CONFLITO DE INTERESSES}

Não se aplica.

\section{LICENÇA DE USO}

Este artigo está licenciado sob a Licença Creative Commons CC-BY. Com essa licença você pode compartilhar, adaptar, criar para qualquer fim, desde que atribua a autoria da obra.

\section{HISTÓRICO}

Recebido em: 20-04-2020

Aprovado em: 22-09-2020 